\section{Glabellar Reflex}

Stephen P. Salloway

Butler Hospital Alpert Medical School of Brown

University, Providence, RI, USA

\section{Synonyms}

Myerson's sign

\section{Definition}

The glabellar reflex is elicited by repeatedly tapping the patient between the eyebrows (the glabella area), causing them to blink. Normally, the adult patient habituates to the stimulus, and ceases blinking after a few taps. If blinking persists, it is abnormal in adults. It is best to stand on the side of the patient and softly tap the glabellar area with a reflex hammer from above to avoid eliciting the blink reflex to threat. It is one of the frontal release signs, primitive reflexes that are normal in infants, disappear with brain maturation allowing inhibition, and reappear (are "released") in disorders that affect the frontal lobes. Like most primitive reflexes, the glabellar reflex probably has evolutionary/adaptive advantage in infant apes, protecting the eyes from threat.

\section{References and Readings}

Goetz, C. G. (2007). Textbook of clinical neurology (3rd ed.). Philadelphia: Saunders. 